\section{ENZYME REPLACEMENT THERAPY WITH VELAGLUCERASE ALFA IMPROVES KEY CLINICAL PARAMETERS IN A PEDIATRIC SUBGROUP WITH TYPE 1 GAUCHER DISEASE}

\author{
A. Zimran ${ }^{1}$, D.E. Gonzalez², D. Elstein ${ }^{1}$, \\ E. Crombez ${ }^{3}$, K. Bhirangi ${ }^{3}$
}

${ }^{1}$ Shaare Zedek Medical Center, Jerusalem, Israel, ${ }^{2}$ Sanatorio Español, Asunción, Paraguay, ${ }^{3}$ Shire Human Genetic Therapies, Cambridge, MA, USA

Background and aims: A randomized, doubleblind, Phase III trial of velaglucerase alfa in type 1 Gaucher disease provides an opportunity to examine outcomes in pediatric patients.

Methods: Of 25 patients in the trial, 7 pediatric patients $(28 \%)$ were enrolled and randomized to receive velaglucerase alfa at $60 \mathrm{U} / \mathrm{kg}(\mathrm{n}=4)$ or $45 \mathrm{U} /$ $\mathrm{kg}(\mathrm{n}=3)$ as a 1-hour infusion, every other week for 12 months.

Results: At 12 months, the mean hemoglobin concentration increased in both groups $(60 \mathrm{U} / \mathrm{kg}$ : $16.3 \%$ increase, $1.74 \mathrm{~g} / \mathrm{dL}, 95 \% \mathrm{Cl}: 0.72,2.78 ; 45$ U/kg: $24.7 \%$ increase, $2.77 \mathrm{~g} / \mathrm{dL}, 95 \% \mathrm{Cl}:-0.99$, 6.53). Mean platelet counts also increased in both groups (60 U/kg: $26.4 \%$ increase, $+49.9 \times 10^{9} / \mathrm{L}$, 95\% Cl: $-32.1,+131.9 ; 45 \mathrm{U} / \mathrm{kg}: 38.9 \%$ increase, $+60.3 \times 10 \% / \mathrm{L}, 95 \% \mathrm{Cl}:-103.1,+223.7)$. Mean spleen volume, normalized by body weight, decreased in both groups (60 U/kg: $64.6 \%$ decrease, $-2.1 \mathrm{~cm}^{3}$, $95 \% \mathrm{Cl}:-5.3,+1.1 ; 45 \mathrm{U} / \mathrm{kg}: 47.6 \%$ decrease, -0.7 $\left.\mathrm{cm}^{3}, 95 \% \mathrm{Cl}:-2.6,+1.2\right)$ as did mean liver volume (60 U/kg: 18.3\%, $-0.7 \mathrm{~cm}^{3}, 95 \% \mathrm{Cl}:-1.4,0.0 ; 45 \mathrm{U} /$ kg: $10.6 \%$ decrease, $\left.-0.3 \mathrm{~cm}^{3}, 95 \% \mathrm{Cl}:-1.7,+1.1\right)$. No children developed antibodies to velaglucerase alfa, experienced a severe or a serious treatmentemergent adverse event, or discontinued due to an adverse event.

Conclusions: In these pediatric patients with type 1 Gaucher disease, velaglucerase alfa was generally well tolerated at doses of $60 \mathrm{U} / \mathrm{kg}$ and $45 \mathrm{U} / \mathrm{kg}$, and provided clinically meaningful improvements in disease parameters.

Velaglucerase alfa is approved in the U.S.

\section{CLINICAL STUDY OF ACCIDENTAL ACUTE POISOINING IN CHILDREN UNDER 3 YEARS OF AGE}

\section{S. Stefanovic ${ }^{1}$, A. Vasilevska ${ }^{1}$, V. Stefanovic ${ }^{2}$, V. Stefanovic ${ }^{3}$ \\ ${ }^{1}$ Institute for Children and Youth Health Care of Vojvodina, ' 2 Health Center 'Novi Sad', ${ }^{3}$ Medical Faculty Novi Sad, Novi Sad, Serbia}

Background: Acute poisoning in children, especially in infants and toddlers is caused by accident Young children are especially vulnerable categorie as they are exposed to many potential toxins in age when they are curios toward environment and have need for great physical activity .

Parents have the greatest responsibility for the prevention of acute poisoning in children. They should pay attention to issues that are known as "poisoning prevention 4R": "to recognize," "to remove", "to be ready," to "respond. "

Methods: It is a prospective study for 3 years period ( 2006-2009) that includes every case of acute poisoning at our hospital

Results: There were 98 children , 68 of them were younger than 3 years of age -even $70,88 \%$. at this age. $94 \%$ had access to toxic substances at their home, In $38 \%$ of cases, parents had currently seen the act of poisoning but it was late to stop as they were busy with other actions then taking care of their children.

The most frequent cause of acute poisoning (64\%) are drugs - mostly sedatives and antihypertensive drugs In few cases it was due to replacement or overdose of drug given by parents.

In $15 \%$ acute poisoning was caused by ingestion of industrial products for household and $11 \%$ due to pesticids

Conclusion: Problem can be prevented if more attention is paid to educate parents how to recognize toxic substance, safely store it at home and be ready to give first aid to their child if poisoning happens 